\title{
Synthesis and Properties of Novel Polyamides Based on a Benzonorbornane Dietheramine
}

\author{
Sheng-Huei HSIAO ${ }^{\dagger}$ and Tai-Lin HuANG \\ Department of Chemical Engineering, Tatung University, \\ 40 Chungshan North Road, 3rd Section, Taipei 104, Taiwan, Republic of China
}

(Received December 3, 2001; Accepted January 8, 2002)

\begin{abstract}
A set of new aromatic polyamides containing ether and benzonorbornane units were synthesized by the direct phosphorylation polycondensation of 3,6-bis(4-aminophenoxy)benzonorbornane (BAPBN) with various aromatic dicarboxylic acids. The polymers were produced with high yields and medium inherent viscosities $\left(0.40-0.82 \mathrm{dL} \mathrm{g}^{-1}\right)$. The polyamides based on rigid diacids showed limited solubility in organic solvents and could not afford ductile films. The polyamides derived from less rigid diacids were readily soluble in polar organic solvents and gave flexible and tough films via solvent casting. These polyamides showed glass-transition temperatures in the range of $200-269^{\circ} \mathrm{C}$ (by DSC), softening temperatures in the range of $220-289^{\circ} \mathrm{C}$ (by TMA), and $10 \%$ weight loss temperatures in excess of $450^{\circ} \mathrm{C}$ (by TGA). For a comparative study, a series of analogous polyamides based on 1,4-bis(4-aminophenoxy)benzene (BAPB) were also prepared and characterized.
\end{abstract}

KEY WORDS Benzonorbornane / Dietheramine / Polyamide /

Aromatic polyamides (aramids) have been well known for their high temperature stability, excellent mechanical strength and good chemical resistance, which qualify them as high-performance polymeric materials. ${ }^{1,2}$ However, most aramids suffer poor processability due to limited solubility in common organic solvents and high glass-transition $\left(T_{\mathrm{g}}\right)$ and softening $\left(T_{\mathrm{s}}\right)$ temperatures. Considerable effort has been made to increase the processability and solubility of aramids by structural modification. One of the approaches to increasing solubility and lowering $T_{\mathrm{g}}$ and $T_{\mathrm{s}}$ is the introduction of flexible bonds in the polymer backbone and bulky pendant groups along the main chain. ${ }^{3-11}$ In recent years, we have reported the synthesis and properties of aramids with aryl ether and bulky pendant groups, such as phenyl, tert-butyl, 9,9-fluorenylidene, and 2,2-adamantylidene groups. ${ }^{12-15}$ The polyamides showed a good solubility in polar organic solvents and excellent mechanical properties. They also showed a reasonable level of thermal stability and exhibited moderate $T_{\mathrm{g}} \mathrm{s}$ potential for modability. In connection with our interest in preparing easily processable high-performance polymers, this study deals with the synthesis and basic characterization of a series of novel aramids derived from a new benzonorbornane dietheramine, 3,6-bis(4aminophenoxy)benzonorbornane (BAPBN), with various aromatic dicarboxylic acids. The properties were compared with those of the structurally related aramids without the pendent fused norbornane structure. A major objective was to study the effect of the lateral nor- bornane groups on basic properties of the aramids, such as solubility in organic solvents, thermal transitions and thermal stability, crystallinity, and film formimg ability.

\section{EXPERIMENTAL}

\section{Materials}

1,4-Bis(4-aminophenoxy)benzene (BAPB; from TCI) was used as received. As described in a separate paper, ${ }^{16}$ 3,6-bis(4-aminophenoxy)benzonorbornane (BAPBN) (mp $175-176^{\circ} \mathrm{C}$ ) was prepared by the aromatic nucleophilic substitution reaction of $p$-chloronitrobenzene and 3,6dihydroxybenzonorbornane in the presence of potassium carbonate, giving the 3,6-bis(4-nitrophenoxy)benzonorbornane, and followed by reduction of the dinitro compound using hydrazine as the reducing agent and palladium on charcoal as the catalyst. The aromatic dicarboxylic acids such as terephthalic acid (1a; from Fluka), isophthalic acid (1b; from Fluka), 4,4'-biphenyldicarboxylic acid (1c; from TCI), 4,4'-oxydibenzoic acid (1d; from TCI), 4,4'-sulfonyldibenzoic acid (1e; from New Japan Chemical Co.), 2,2-bis(4-carboxyphenyl)1,1,1,3,3,3-hexafluoropropane (1f; from Chriskev), 2,6-naphthalenedicarboxylic acid (1g; from TCI), 1,4-naphthalenedicarboxylic acid (1h; from Wako), 5-tert-butylisophthalic acid (1i; from Aldrich) and 3-(4-carboxyphenyl)-2,3-dihydro-1,1,3-trimethyl- $1 \mathrm{H}$ indene-5-carboxylic acid (1j; from Acros) was used as received. $N$-Methyl-2-pyrrolidone (NMP) and pyridine

${ }^{\dagger}$ To whom correspondence should be addressed (E-mail: shhsiao@ttu.edu.tw) 
were purified by distillation under reduced pressure over calcium hydride and stored over $4 \AA$ molecular sieves. Triphenyl phosphite (TPP, from Fluka) was purified by distillation under reduced pressure. Commercially obtained anhydrous calcium chloride $\left(\mathrm{CaCl}_{2}\right.$; from Wako) was dried under vacuum at $180^{\circ} \mathrm{C}$ for $8 \mathrm{~h}$.

\section{Polymer Synthesis}

A typical synthetic procedure for polyamide $\mathbf{3 d}$ is described as follows. A mixture of $0.5376 \mathrm{~g}(1.5 \mathrm{mmol})$ of diamine BAPBN, $0.3873 \mathrm{~g}(1.5 \mathrm{mmol})$ of $4,4^{\prime}$ oxydibenzoic acid (1d), $0.3 \mathrm{~g}$ of calcium chloride, 2 $\mathrm{mL}$ of TPP, $0.8 \mathrm{~mL}$ of pyridine, and $3 \mathrm{~mL}$ of NMP was heated with stirring at $120^{\circ} \mathrm{C}$ for $3 \mathrm{~h}$. As the polycondensation proceeded, the reaction mixture became viscous gradually. The resultant solution of the polymer was poured slowly into $300 \mathrm{~mL}$ of stirred methanol giving rise to a tough, fiber-like polymer precipitate. The product was collected by filtration, thoroughly washed by methanol and hot water, and dried. The inherent viscosity of the polyamide (3d) was $0.75 \mathrm{dL} \mathrm{g}^{-1}$, measured at a concentration of $0.5 \mathrm{~g} \mathrm{dL}^{-1}$ in DMAc containing 5 wt $\% \mathrm{LiCl}$ at $30^{\circ} \mathrm{C}$.

\section{Preparation of the Polyamide Films}

A solution of polymer was made by dissolving about $0.8 \mathrm{~g}$ of the polyamide in $8 \mathrm{~mL}$ of hot DMAc to afford an approximate $10 \mathrm{wt} \%$ solution. The homogeneous solution was poured into a $9 \mathrm{~cm}$ diameter glass culture dish, which was placed in a $90^{\circ} \mathrm{C}$ oven for $12 \mathrm{~h}$ to evaporate the solvent. The semi-dried polyamide film was stripped off from the glass surface and further dried in vacuo at $160^{\circ} \mathrm{C}$ for $6 \mathrm{~h}$. The obtained films showed about $0.06 \mathrm{~mm}$ in thickness and were used for X-Ray diffraction measurements, tensile tests, solubility tests, and thermal analyses.

\section{Measurements}

Elemental analysis was made on a Perkin-Elmer $2400 \mathrm{CHN}$ analyzer. IR spectra were recorded on a Horiba FT-720 Fourier transform infrared (FT-IR) spectrometer. ${ }^{1} \mathrm{H}$ NMR and ${ }^{13} \mathrm{C}$ NMR spectra were measured on a JEOL EX 400 spectrometer with DMSO- $d_{6}$ as the solvent and tetramethylsilane as the internal reference. The inherent viscosities of the polyamides were measured with a Cannon-Fenske viscometer at $30^{\circ} \mathrm{C}$. An Instron universal tester model 1130 with a load cell of $5 \mathrm{~kg}$ was used to study the stress-strain behavior of the polyimide film samples. A gauge length of $2 \mathrm{~cm}$ and a crosshead speed of $5 \mathrm{~mm} \mathrm{~min}{ }^{-1}$ were used for this study. Measurements were performed at room temperature with film specimens $(0.5 \mathrm{~cm}$ wide, $6 \mathrm{~cm}$ long, and about $0.06 \mathrm{~mm}$ thick), and an average of at least five individual determinations was used. Wide-angle XRay diffraction measurements were performed at room temperature (about $25^{\circ} \mathrm{C}$ ) on a Siemens Kristalloflex D5000 X-Ray diffractometer, using nickel-filtered $\mathrm{Cu}$ $K_{\alpha}$ radiation $(\lambda=1.5418 \AA$, operating at $40 \mathrm{kV}$ and $20 \mathrm{~mA}$ ). The scanning rate was $3^{\circ} \mathrm{min}^{-1}$ over a range of $2 \theta=5-45^{\circ}$. Thermogravimetric analysis (TGA) was conducted with a Perkin-Elmer Pyris 1 TGA. Experiments were carried out on approximately 3$5 \mathrm{mg}$ of samples in flowing nitrogen or air (flow rate $20 \mathrm{~cm}^{3} \mathrm{~min}^{-1}$ ) at a heating rate of $20^{\circ} \mathrm{C} \mathrm{min}{ }^{-1}$. DSC analyses were performed on a Perkin-Elmer Pyris 1 DSC at a heating rate of $20^{\circ} \mathrm{C} \mathrm{min}^{-1}$ under nitrogen. Glass transition temperatures $\left(T_{\mathrm{g}}\right)$ were read at the middle of the transition in the heat capacity and were taken from the second heating scan after quick cooling from $400^{\circ} \mathrm{C}$ at a cooling rate of $200^{\circ} \mathrm{C} \mathrm{min}^{-1}$. Thermomechanical analysis (TMA) was conducted with a PerkinElmer TMA 7 instrument. The TMA experiments were conducted from $40^{\circ} \mathrm{C}$ to $300^{\circ} \mathrm{C}$ at a scan rate of $10^{\circ} \mathrm{C}$ $\mathrm{min}^{-1}$ using a penetration probe $1.0 \mathrm{~mm}$ in diameter under an applied constant load of $10 \mathrm{mN}$. Softening temperatures $\left(T_{\mathrm{S}}\right)$ were taken as the onset temperature of probe displacement on the TMA traces.

\section{RESULTS AND DISCUSSION}

\section{Polymer Synthesis}

According to the phosphorylation technique first described by Yamazaki and co-workers, ${ }^{17,} 18$ two series of aromatic polyamides $\mathbf{2} \mathbf{a}-\mathbf{j}$ and $\mathbf{3 a}-\mathbf{j}$ were synthesized from either diamine BAPB or BAPBN with various aromatic dicarboxylic acids 1a-j (Scheme 1). The polymerization was carried out via solution polycondensation using TPP and pyridine (PY) as condensing agents in the NMP solution containing dissolved calcium chloride. The reaction conditions and results are summarized in Table I. The resulting BAPB- and BAPBNbased polyamides had inherent viscosities in the range of $0.37-1.20 \mathrm{dL} \mathrm{g}^{-1}$ and $0.40-0.82 \mathrm{dL} \mathrm{g}^{-1}$, respectively. In some cases of the polyamides (such as $\mathbf{2 a}, \mathbf{2 c}, \mathbf{2 d}$, $\mathbf{2 g}, \mathbf{2 h}, \mathbf{3 c}$, and $\mathbf{3 h}$ ), precipitation occurred during the polymerization due to insolubility of the polymers, and adding more solvent or salt in order to carry out the reaction in a homogeneous phase has met with failure in obtaining clear and viscous polymer solutions. A powdery product was obtained when these polymer solutions were poured into methanol. The insolubility for these polyamides may be attributed to their high level of crystallinity, which will be discussed subsequently. No attempts were made to cast the powdery products into polymer films. For the polyamides with good solubility, the polymerization proceeded homogeneously 


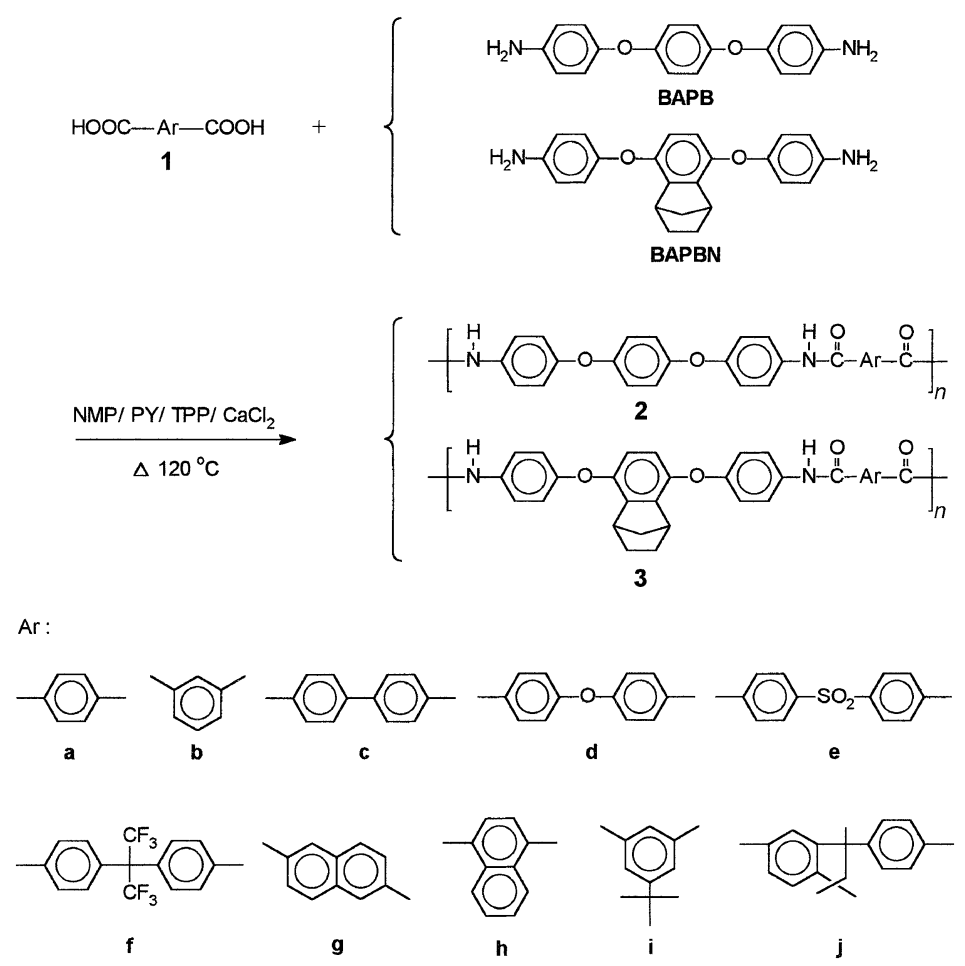

Scheme 1. Synthesis of polyamides.

Table I. Synthesis conditions, inherent viscosity, and film quality of polyamides

\begin{tabular}{|c|c|c|c|c|c|c|}
\hline \multirow[b]{2}{*}{$\begin{array}{c}\text { Polymer } \\
\text { code }\end{array}$} & \multicolumn{4}{|c|}{ Amount of reagents used ${ }^{\mathrm{a}}$} & \multirow{2}{*}{$\frac{\eta_{\text {inh }^{\mathrm{b}}}}{\mathrm{dL} \mathrm{g}^{-1}}$} & \multirow{2}{*}{$\begin{array}{c}\text { Film } \\
\text { quality }^{\mathrm{c}}\end{array}$} \\
\hline & $\frac{\mathrm{NMP}}{\mathrm{mL}}$ & $\frac{\text { Pyridine }}{\mathrm{mL}}$ & $\frac{\mathrm{TPP}}{\mathrm{mL}}$ & $\frac{\mathrm{CaCl}_{2}}{\mathrm{~g}}$ & & \\
\hline $2 \mathbf{a}$ & $10+5$ & 2.5 & 1.5 & $1.0+0.5$ & 0.44 & $-^{d}$ \\
\hline $2 b$ & 3 & 0.8 & 1.5 & 0.3 & 1.20 & $\mathrm{~F}$ \\
\hline $2 \mathrm{c}$ & $10+5$ & 2.5 & 1.5 & $1.0+0.5$ & 0.37 & - \\
\hline 2d & 3 & 0.8 & 1.5 & 0.3 & 0.73 & - \\
\hline $2 e$ & $3+2$ & 0.8 & 1.5 & 0.3 & 0.94 & $\mathrm{~F}$ \\
\hline $2 f$ & 3 & 0.8 & 1.5 & 0.3 & 0.80 & $\mathrm{~F}$ \\
\hline $2 \mathrm{~g}$ & 7.5 & 1.8 & 1.5 & 0.8 & 0.71 & - \\
\hline $2 \mathrm{~h}$ & 3 & 0.8 & 1.5 & 0.3 & 0.92 & - \\
\hline $2 \mathbf{i}$ & 3 & 0.8 & 1.5 & 0.3 & 0.61 & $\mathrm{~F}$ \\
\hline $2 j$ & 3 & 0.8 & 1.5 & 0.3 & 0.63 & $\mathrm{~F}$ \\
\hline $3 \mathbf{a}$ & $3+1$ & 1.0 & 1.5 & $0.3+0.1$ & 0.75 & B \\
\hline $3 \mathbf{b}$ & 3 & 0.8 & 1.5 & 0.3 & 0.40 & $\mathrm{~F}$ \\
\hline $3 c$ & $3+1$ & 0.8 & 1.5 & $0.3+0.1$ & 0.72 & - \\
\hline 3d & 3 & 0.8 & 1.5 & 0.3 & 0.75 & $\mathrm{~F}$ \\
\hline $3 e$ & 3 & 0.8 & 1.5 & 0.3 & 0.59 & $\mathrm{~F}$ \\
\hline $3 f$ & 3 & 0.8 & 1.5 & 0.3 & 0.59 & $\mathrm{~F}$ \\
\hline $3 g$ & 3 & 0.8 & 1.5 & 0.3 & 0.82 & B \\
\hline $3 h$ & 3 & 0.8 & 1.5 & 0.3 & 0.61 & - \\
\hline $3 \mathbf{i}$ & 3 & 0.8 & 1.5 & 0.3 & 0.51 & $\mathrm{~F}$ \\
\hline $3 \mathbf{j}$ & 3 & 0.8 & 1.5 & 0.3 & 0.46 & $\mathrm{~F}$ \\
\hline
\end{tabular}

${ }^{a}$ The polymerization was carried out with $1.5 \mathrm{mmol}$ of each monomer at $120^{\circ} \mathrm{C}$ for $3 \mathrm{~h}$. ${ }^{\mathrm{b}}$ Inherent viscosity of the polyamides measured in DMAc at a concentration of $0.5 \mathrm{~g} \mathrm{dL}^{-1}$ at $30^{\circ} \mathrm{C}$. ${ }^{\circ}$ Films were cast by slow evaporation of solutions in DMAc. B: brittle film (cracked upon creasing); F: flexible film. ${ }^{\mathrm{d}}$ Insoluble in all the available organic solvents.

throughout the reaction and gave a clear and viscous polymer solution. A tough, stringy precipitate could be obtained when pouring the resulting polymer solutions into stirred methanol. Most of the soluble polyamides could be fabricated into strong and flexible films via solution casting, indicating that these polyamides had medium to high molecular weights. Structural features of these polyamides were confirmed by FT-IR and 


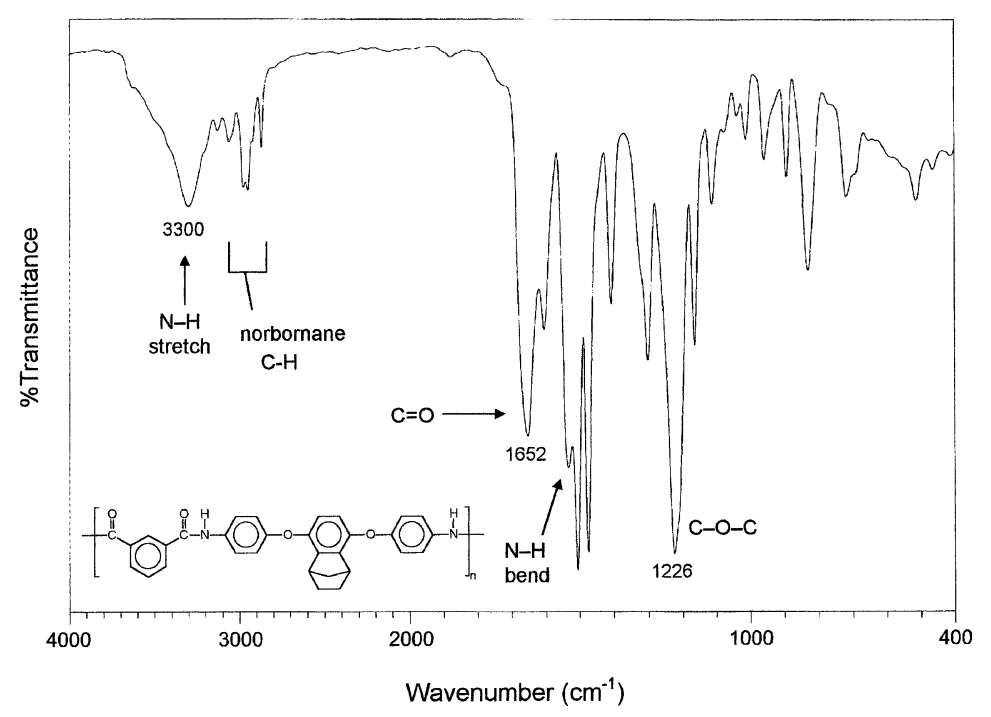

Figure 1. The IR spectrum of polyamide $\mathbf{3 b}$.

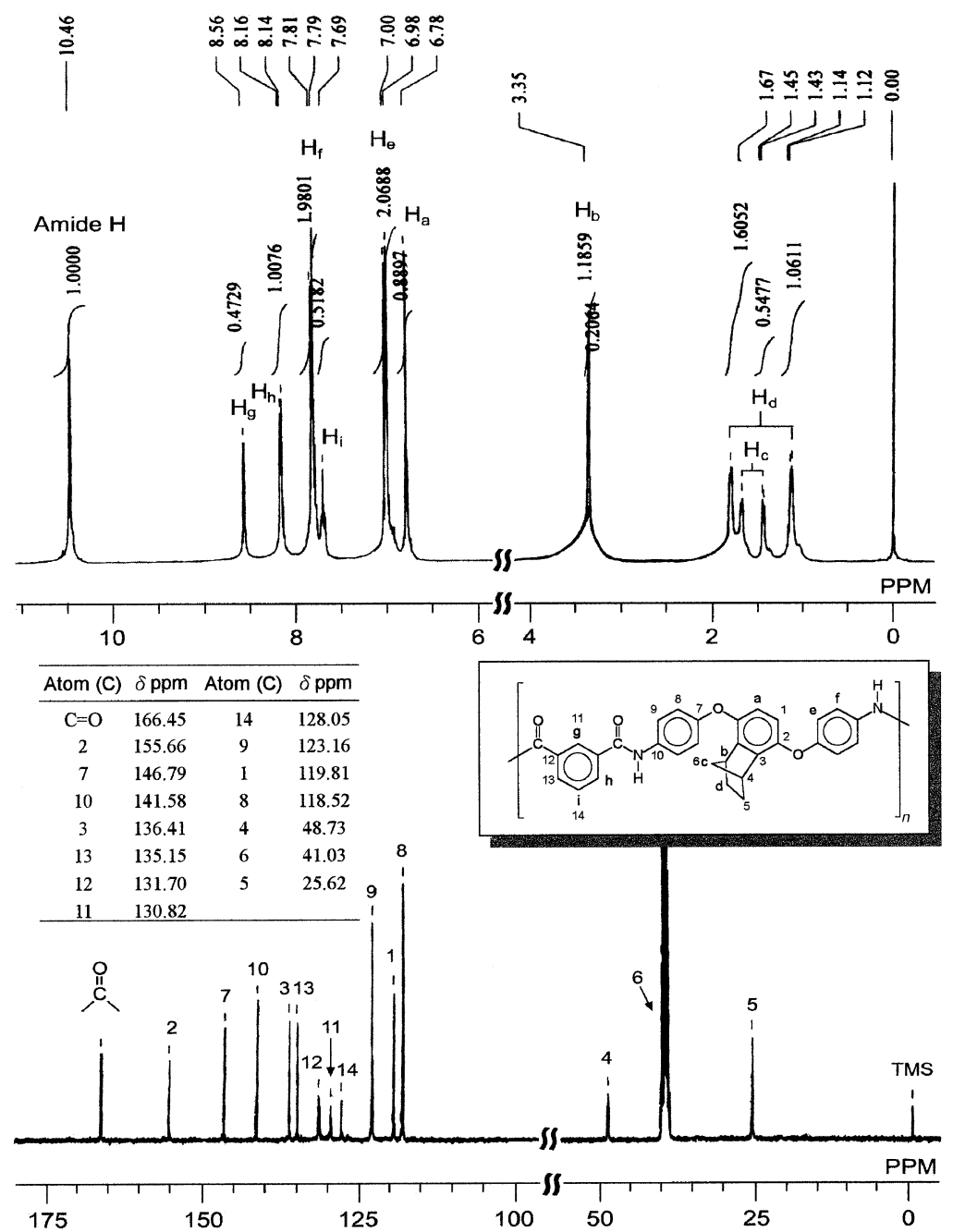

Figure 2. ${ }^{1} \mathrm{H}$ NMR and ${ }^{13} \mathrm{C}$ NMR spectra of polyamide $\mathbf{3 b}$ in DMSO- $d_{6}$.

NMR spectroscopy. They exhibited characteristic IR absorption bands of the amide group around $3300(\mathrm{~N}-$ $\mathrm{H}$ stretching), $1650(\mathrm{C}=\mathrm{O}$ stretching $)$, and $1530 \mathrm{~cm}^{-1}$ (N-H bending), along with the characteristic absorp- tion band of aryl ether stretching near $1220 \mathrm{~cm}^{-1}$. A typical IR spectrum for the thin film of polyamide $\mathbf{3 b}$ is illustrated in Figure 1. Figure 2 illustrates the ${ }^{1} \mathrm{H}$ $\mathrm{NMR}$ and ${ }^{13} \mathrm{C}$ NMR spectra of polymer $\mathbf{3 b}$, where all 


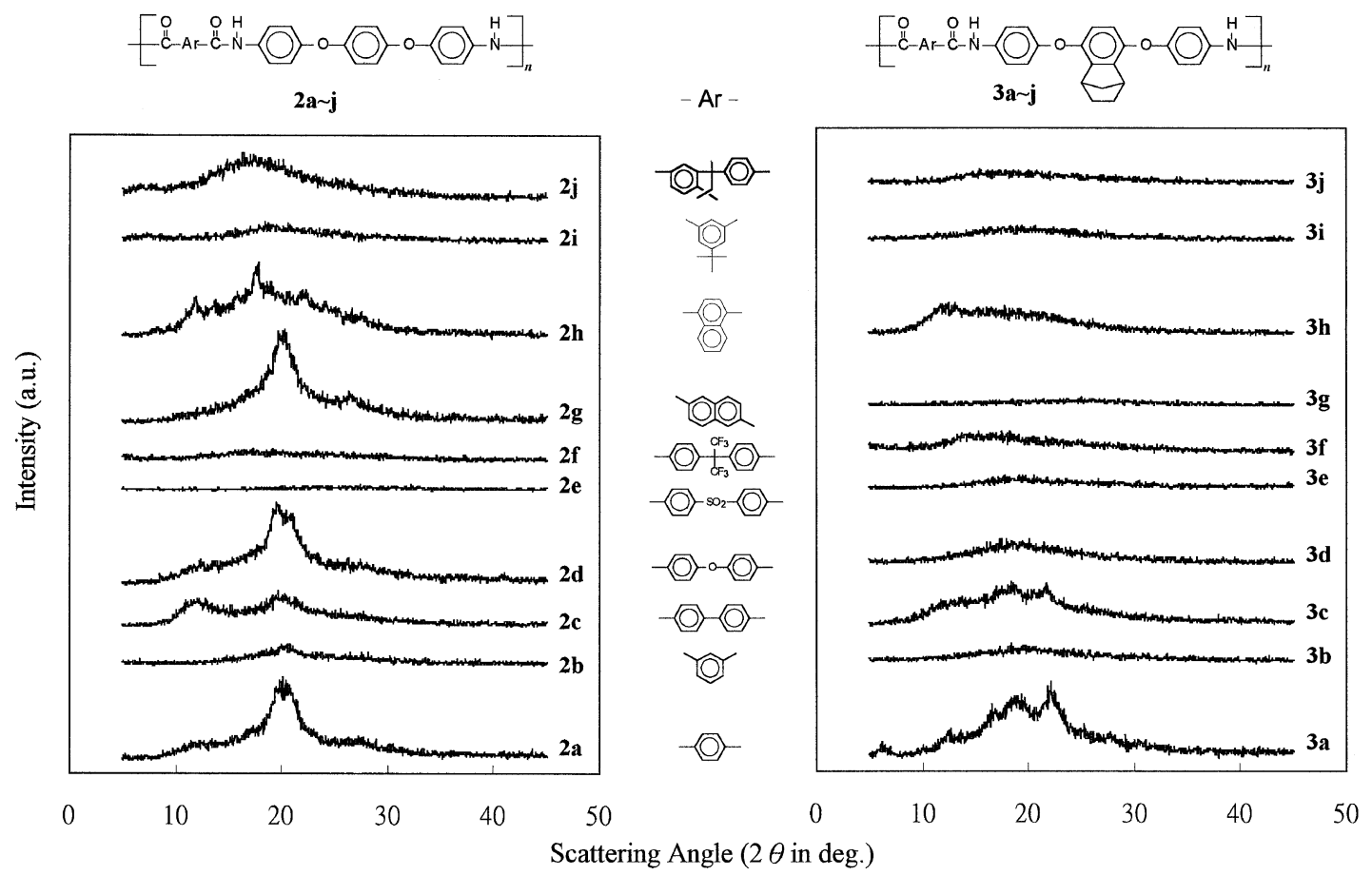

Figure 3. Wide-angle X-Ray diffractograms of polyamides $\mathbf{2} \mathbf{a}-\mathbf{j}$ and $\mathbf{3 a} \mathbf{a}$.

the peaks have been readily assigned to the hydrogen and carbon atoms of the repeating unit.

\section{Polymer Characterization}

All the polymers were structurally characterized by $\mathrm{X}$-Ray diffraction studies. As can be seen from the diffraction patterns shown in Figure 3, the BAPB-based polyamides derived from rigid diacids such as $\mathbf{2 a}, \mathbf{2 c}$, $\mathbf{2 d}, \mathbf{2 g}$, and $\mathbf{2 h}$ showed some diffraction signals of medium to high intensity assignable to a semicrystalline polymer. In contrast, almost all BAPBN-based polyamides except for $\mathbf{3 a}, \mathbf{3 c}$, and $\mathbf{3 h}$ displayed a nearly completely amorphous pattern. When comparing the $\mathrm{X}$-Ray diffraction patterns of the analogous pairs of $\mathbf{2 d} / \mathbf{3 d}$ and $\mathbf{2 g} / \mathbf{3 g}$, one can see an obvious effect of the introduction of the pendent norbornane group on decreasing the crystallinity of these polyamides. The incorporation of bulky side groups produces a wider separation of polymer chains, a weakening of intermolecular hydrogen bonding, and a lowering of chain packing efficiency with a gain of free volume, thus resulting in a decrease in crystallinity.

The solubility behavior of polyamides was tested qualitatively, and the results are presented in Table II. Polymers derived from rigid and symmetrical dicarboxylic acids, such as $\mathbf{1 a}, \mathbf{1 c}, \mathbf{1 g}$, and $\mathbf{1 h}$, generally showed a lower solubility due to a high level of crystallinity. Almost all of them were insoluble in any of the solvents tested. The amorphous polyamides exhibited a higher solubility; they were soluble in most polar aprotic solvents. The polyamides derived from the fluorinated diacid (1f) also showed solubility in less efficient $m$-cresol and THF. In general, the solubility of the BAPBN-based polyamides was higher than that of the BAPB-based polyamides. As comparing the solubility of the analogous polymer pairs such as $\mathbf{2 b} / \mathbf{3 b}$ and $\mathbf{2 d} / \mathbf{3 d}$, it is evident that the introduction of norbornane units improves the solubility of polyamides. The reason is similar to that cited above.

The tensile properties of the polyamide films are summarized in Table III. All the soluble polyamides could be processed to flexible, creasable films by casting from solutions in DMAc. Their tensile strengths, elongations to break, and initial moduli were in the range of 80-111 $\mathrm{MPa}, 7-45 \%, 1.8-2.7 \mathrm{GPa}$, respectively. In general, the BAPBN polyamides behaved as strong and rigid materials. The restricted movement of the polymer chains due to the benzonorbornane moiety may explain the lack of ductility.

DSC, TMA, and TGA were used to evaluate the thermal properties of all polymers. The thermal behavior data of the polyamides are shown in Table IV. $T_{\mathrm{g}}$ of these polyamides was obtained from the middlepoint temperature of baseline shift on the second DSC heating trace (heating rate $=20^{\circ} \mathrm{C} \mathrm{min}{ }^{-1}$ ) after rapid cooling from $400^{\circ} \mathrm{C}$ (cooling rate $=200^{\circ} \mathrm{C}$ $\left.\mathrm{min}^{-1}\right)$. In the BAPBN-based polyamides $(\mathbf{3 a}-\mathbf{j})$, only the polyamides $\mathbf{3 a}$ and $\mathbf{3 c}$ that were semicrystalline showed no discernible $T_{\mathrm{g}} \mathrm{s}$ on their DSC curves. The other BAPBN polyamides showed $T_{\mathrm{g}}$ values between $200^{\circ} \mathrm{C}$ and $269^{\circ} \mathrm{C}$ by DSC, generally following the increasing order of chain rigidity, steric hindrance, and 
Table II. Solubility behavior of polyamides

\begin{tabular}{|c|c|c|c|c|c|c|}
\hline \multirow{2}{*}{$\begin{array}{c}\text { Polymer } \\
\text { code }\end{array}$} & \multicolumn{6}{|c|}{ Solubility $^{\mathrm{a}}$} \\
\hline & NMP & DMAc & DMSO & DMF & $m$-Cresol & THF \\
\hline $2 a$ & - & - & - & - & - & - \\
\hline $2 b$ & + & + & - & + & - & - \\
\hline $2 c$ & - & - & - & - & - & - \\
\hline 2d & - & - & - & - & - & - \\
\hline $2 e$ & + & + & $+\mathrm{h}$ & - & - & - \\
\hline $2 f$ & + & + & + & + & + & + \\
\hline $2 \mathrm{~g}$ & - & - & - & - & - & - \\
\hline $2 \mathrm{~h}$ & - & - & - & - & - & - \\
\hline $2 \mathbf{i}$ & + & + & + & + & - & - \\
\hline $2 j$ & + & + & - & + & + & - \\
\hline $3 \mathbf{a}$ & + & - & - & - & - & - \\
\hline $3 b$ & + & + & + & + & + & - \\
\hline $3 c$ & - & - & - & - & - & - \\
\hline 3d & + & + & + & + & + & - \\
\hline $3 e$ & + & + & + & + & + & - \\
\hline $3 f$ & + & + & + & + & + & + \\
\hline $3 g$ & $+\mathrm{h}$ & - & - & - & + & - \\
\hline $3 h$ & - & - & $+\mathrm{h}$ & - & + & - \\
\hline $3 \mathbf{i}$ & + & + & + & + & + & - \\
\hline $3 \mathbf{j}$ & + & + & + & + & + & + \\
\hline
\end{tabular}

${ }^{a}$ Qualitative solubility tested with $10 \mathrm{mg}$ of sample in $1 \mathrm{~mL}$ of the solvent. +: soluble at room temperature; $+\mathrm{h}$ : soluble on heating at $100^{\circ} \mathrm{C} ;-$ : insoluble even on heating.

Table III. Mechanical properties of polyamide films

\begin{tabular}{|c|c|c|c|}
\hline Polymer & Tensile strength & Elongation to break & Initial modulus \\
\hline code & $\mathrm{MPa}$ & $\%$ & $\mathrm{GPa}$ \\
\hline $2 \mathbf{b}$ & 111 & 45 & 2.7 \\
\hline $2 f$ & 80 & 17 & 1.9 \\
\hline $2 \mathbf{i}$ & 93 & 10 & 2.1 \\
\hline $2 j$ & 71 & 23 & 1.8 \\
\hline $3 \mathbf{b}$ & 98 & 7 & 2.5 \\
\hline 3d & 101 & 12 & 2.2 \\
\hline $3 e$ & 93 & 9 & 2.1 \\
\hline $3 f$ & 100 & 10 & 2.3 \\
\hline $3 \mathbf{i}$ & 97 & 8 & 2.2 \\
\hline $3 \mathbf{j}$ & 83 & 9 & 1.8 \\
\hline
\end{tabular}

polarity of the diacid residues. The lowest $T_{\mathrm{g}}$ of $200^{\circ} \mathrm{C}$ was observed for polyamide 3d derived from etherbridged diacid 1d. The higher $T_{\mathrm{g}}$ values of polyamides $\mathbf{3 g}$ and $\mathbf{3 h}$ are believed to be due to the increased structural rigidity caused by the naphthalene units. For the BAPB-based polyamides $\mathbf{2 a}-\mathbf{j}$, only four amorphous ones displayed well-defined $T_{\mathrm{g}} \mathrm{s}$ on the DSC traces. Although polyamides $\mathbf{2 b}$ and $\mathbf{2 e}$ showed amorphous $\mathrm{X}$-Ray diffraction patterns, they revealed a mediumintensity melting endotherms around 411 and $424^{\circ} \mathrm{C}$, respectively. The results indicate that the BAPB-based polyamides may have a higher crystallization tendency upon heating. As can be seen from Figures 4 and 5, a significant increase in crystallinity was observed if the film sample of polyamide $\mathbf{2 b}$ was annealed at ele- vated temperatures such as $375^{\circ} \mathrm{C}$ for a time. On the contrary, the analogous BAPBN polyamide $\mathbf{3 b}$ showed a weak and broad melting endotherm on the DSC thermograms even after annealing at elevated temperatures. These results also confirmed that the introduction of pendent fused norbornane group is effective in inhibiting the close packing of polymer chains and thus leads to a decrease in crystallinity or crystallization tendency.

The softening temperatures $\left(T_{\mathrm{s}}\right)$ of the polymer film samples were also measured with TMA by the penetration method. They were obtained from the onset temperature of the probe displacement on the TMA trace. A typical TMA thermogram for polymer $\mathbf{3} \mathbf{j}$ is illustrated in Figure 6 . In most cases, the $T_{\mathrm{s}}$ values obtained by the TMA are slightly higher than the $T_{\mathrm{g}}$ values mea- 
Table IV. Thermal behavior data of polyamides

\begin{tabular}{|c|c|c|c|c|c|}
\hline \multirow{2}{*}{$\begin{array}{c}\text { Polymer } \\
\text { code }\end{array}$} & \multirow{2}{*}{$T_{\mathrm{g}}{ }^{\mathrm{a}} /{ }^{\circ} \mathrm{C}$} & \multirow{2}{*}{$T_{\mathrm{s}}^{\mathrm{d}} /{ }^{\circ} \mathrm{C}$} & \multicolumn{2}{|c|}{$T_{\mathrm{d}}^{\mathrm{f} /} /{ }^{\circ} \mathrm{C}$} & \multirow{2}{*}{$\frac{\text { Char yield }^{\mathrm{g}}}{\%}$} \\
\hline & & & $\mathrm{N}_{2}$ & Air & \\
\hline $2 a$ & $-\mathrm{b}$ & $-^{\mathrm{e}}$ & 499 & 535 & 64 \\
\hline $2 b$ & $234(411)^{\mathrm{c}}$ & 234 & 517 & 547 & 66 \\
\hline $2 c$ & - & - & 548 & 545 & 65 \\
\hline 2d & - & - & 498 & 532 & 67 \\
\hline $2 e$ & $-(424)^{\mathrm{c}}$ & - & 501 & 530 & 62 \\
\hline $2 f$ & 240 & 248 & 535 & 553 & 63 \\
\hline $2 \mathrm{~g}$ & - & - & 500 & 527 & 66 \\
\hline $2 h$ & - & - & 498 & 514 & 64 \\
\hline $2 i$ & 221 & 246 & 521 & 530 & 61 \\
\hline $2 \mathbf{j}$ & 238 & 254 & 527 & 523 & 70 \\
\hline $3 a$ & - & 250 & 493 & 505 & 70 \\
\hline $3 b$ & 226 & 237 & 486 & 502 & 67 \\
\hline $3 c$ & - & - & 495 & 466 & 65 \\
\hline 3d & 200 & 232 & 495 & 502 & 69 \\
\hline $3 e$ & 236 & 250 & 483 & 499 & 66 \\
\hline $3 f$ & 227 & 242 & 510 & 530 & 59 \\
\hline $3 g$ & 262 & 280 & 487 & 498 & 70 \\
\hline $3 h$ & 269 & - & 496 & 471 & 66 \\
\hline $3 \mathbf{i}$ & 231 & 253 & 492 & 502 & 64 \\
\hline $\mathbf{3 j}$ & 234 & 262 & 506 & 512 & 71 \\
\hline
\end{tabular}

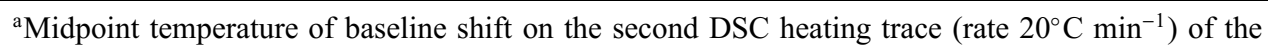
sample after quenching from $400^{\circ} \mathrm{C}$. ${ }^{b}$ No discernible transition. ${ }^{\text {c }}$ Peak top temperature of the melting endotherm on the first DSC heating trace. ${ }^{\mathrm{d}}$ Softening temperature measured by TMA (penetration method) with a constant applied load of $10 \mathrm{mN}$ at a heating rate of $10^{\circ} \mathrm{C} \mathrm{min}^{-1}$. The film samples were heated at $300^{\circ} \mathrm{C}$ for 30 min prior to the TMA experiments. ${ }^{e}$ No available specimen. ${ }^{\mathrm{f}}$ Decomposition temperature at which a $10 \%$ weight loss was recorded by TGA at a heating rate of $20^{\circ} \mathrm{C} \mathrm{min}{ }^{-1}$. ${ }^{\mathrm{g}}$ Residual weight $\%$ at $800^{\circ} \mathrm{C}$ in nitrogen.

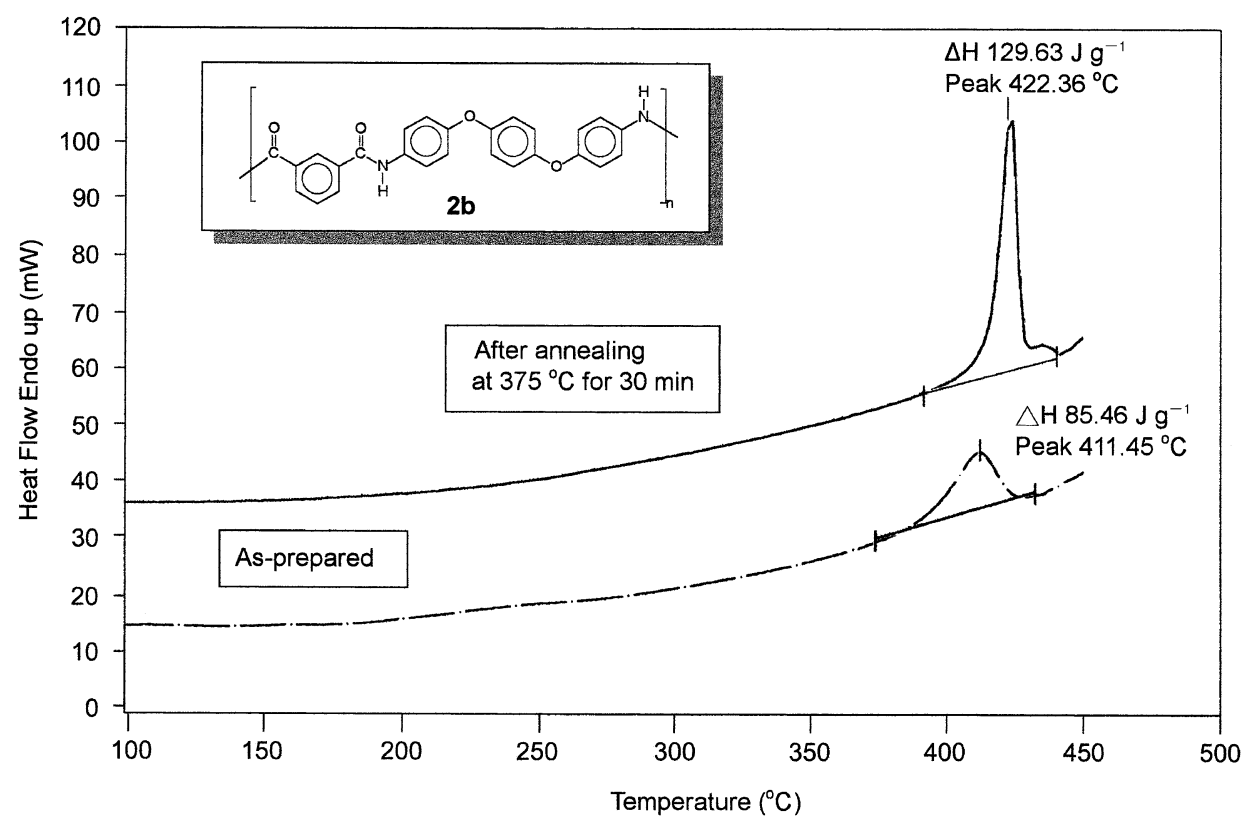

Figure 4. DSC thermograms of the as-prepared sample of polyamide $\mathbf{2} \mathbf{b}$ and that after isothermal annealing.

sured by the DSC experiments. The reason is not very clear; however, this difference may be attributed to different heating story of these samples and the distinctive nature of the testing techniques (thermomechanical vs. calorimetric responses).

The thermal and thermo-oxidative stability of the polyamides was studied by TGA in both nitrogen and air atmospheres. The temperatures at a $10 \%$ weight loss were determined from the original TGA curves 


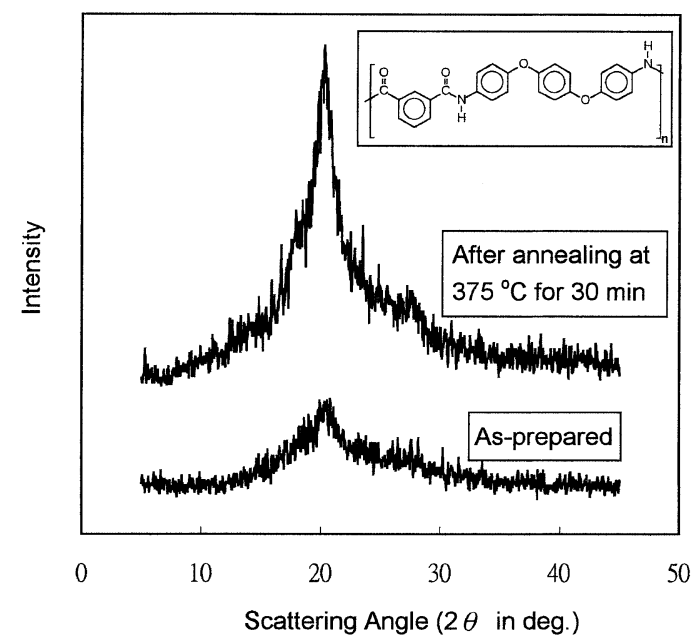

Figure 5. X-Ray diffraction patterns of the as-prepared film of polyamide $\mathbf{2 b}$ and that after isothermal annealing at $375^{\circ} \mathrm{C}$ for 30 $\min$.

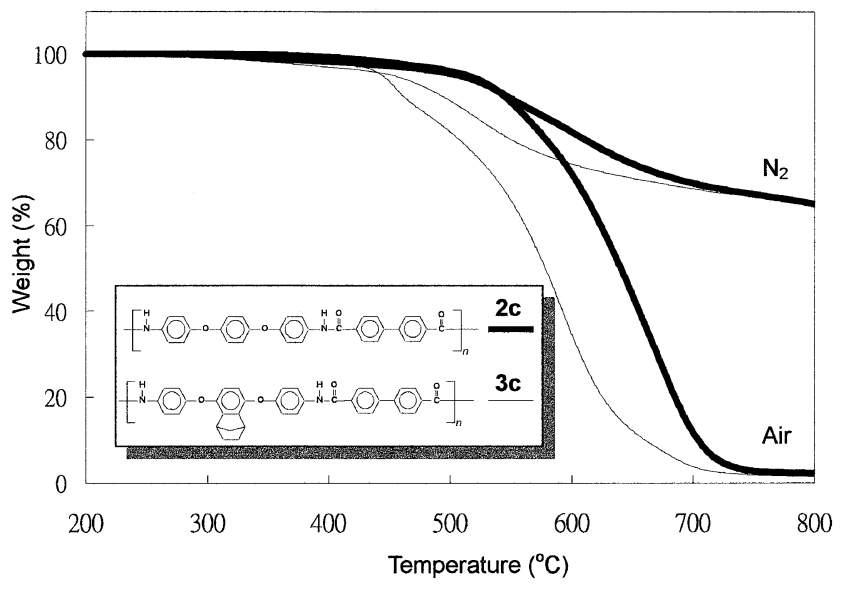

Figure 7. TGA curves of polyamides $2 \mathbf{c}$ and $\mathbf{3 c}$ (Heating rate $=$ $20^{\circ} \mathrm{C} \mathrm{min}^{-1}$ ).

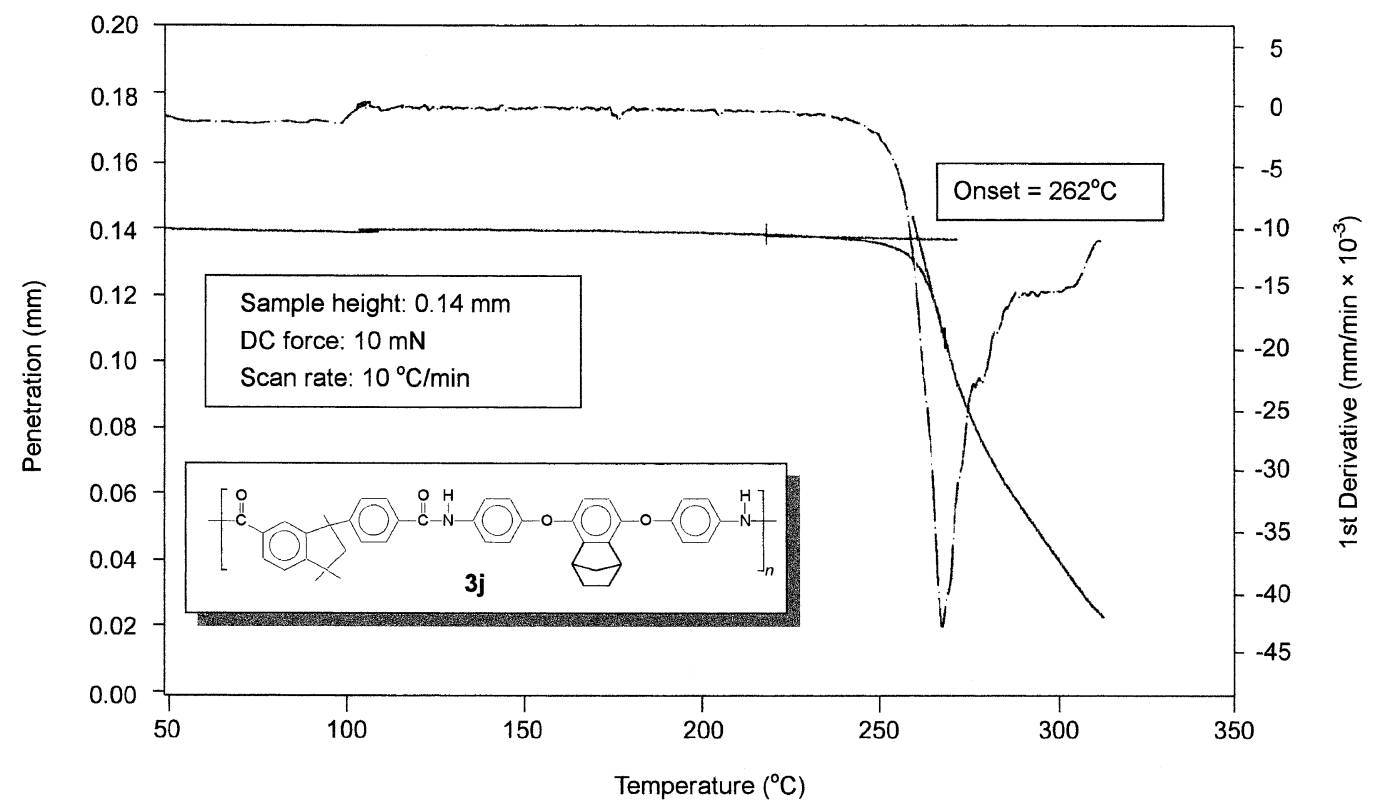

Figure 6. The TMA curve of polyamide $\mathbf{3 j}$.

and are listed in Table IV. All polymer exhibited good thermal stability with insignificant weight loss up to temperatures of approximately $450^{\circ} \mathrm{C}$ in both air and nitrogen atmospheres, and the anaerobic char yield at $800^{\circ} \mathrm{C}$ for all polymers was in the range of 59-71 $w t \%$. Film samples of the BAPBN-based polyamides underwent $10 \%$ weight loss between $483^{\circ} \mathrm{C}$ and $510^{\circ} \mathrm{C}$ in nitrogen and between $466^{\circ} \mathrm{C}$ and $512^{\circ} \mathrm{C}$ in air at a heating rate of $20^{\circ} \mathrm{C} \mathrm{min}{ }^{-1}$. As can be seen, all the BAPBN polyamides showed slightly lower thermal and thermo-oxidative stability compared to that of the BAPB counterparts because of the less stable aliphatic segments. Figure 7 shows a typical set of TGA curves for polyamides $\mathbf{2 c}$ and 3c. It is apparent that the BAPBN polyamide 3c exhibited a lower onset weight loss temperature in comparison with the
BAPB analogue 2c because of the norbornane structure and the amorphous nature. Although a slight detriment in thermal stability caused by the introduction of the benzonorbornane units, most of the BAPBN-based polyamides showed some better properties for practical use such as good solubility and mechanical properties, as compared to the BAPB-based counterparts.

\section{CONCLUSIONS}

A series of novel polyamides with ether and benzonorbornane groups has been successfully synthesized from the diamine BAPBN and various aromatic dicarboxylic acids. The structural effect of the pendent fused norbornane group is to disrupt any regularity in chain packing while increasing the spacing or fractional free 
volume between the polymer chains. The polymers showed decreased crystallinity and improved solubility in organic solvents when compared to similar homologous polyamides without the norbornane moiety. Glass transition and softening temperatures were similar, but thermal resistance was lower as a rule.

Acknowledgments. The authors thank National Science Council for financial support.

\section{REFERENCES}

1. P. E. Cassidy, "Thermally Stable Polymers," Marcel Dekker, Inc., New York, N.Y., 1980.

2. H. H. Yang, 'Aromatic Polyamides' in "Aromatic HighStrength Fibers", John Wiley \& Sons, Inc., New York, N.Y., 1989, p 202.

3. Y. Oishi, H. Takado, M. Yoneyama, M. Kakimoto, and Y. Imai, J. Polym. Sci., Part A: Polym. Chem., 28, 1736 (1990).

4. M. Yamashita, M. Kakimoto, and Y. Imai, J. Polym. Sci., Part A: Polym. Chem., 31, 1513 (1993).

5. G.-S. Liou, M. Maruyama, M. Kakimoto, and Y. Imai, J. Polym. Sci., Part A: Polym. Chem., 31, 2499 (1993).

6. G. Maglio, R. Palumbo, and M. C. Vignola, Macromol. Chem. Phys. 196, 775 (1995).
7. J. F. Espeso, J. G. de la Campa, A. E. Lozano, and J. de Abajo, J. Polym. Sci., Part A: Polym. Chem., 38, 1014 (2000).

8. J. F. Espeso, E. Ferrero, J. G. de la Campa, A. E. Lozano, and J. de Abajo, J. Polym. Sci., Part A: Polym. Chem., 39, 475 (2001).

9. C.-P. Yang and J.-H. Lin, J. Polym. Sci., Part A: Polym. Chem., 31, 2153 (1993).

10. Y.-T. Chern, K.-S. Lin, and S.-C. Kao, J. Appl. Polym. Sci., 68, 315 (1998).

11. S.-H. Hsiao, C.-P. Yang, M.-H. Chuang, and H.-C. Hsiao, J. Polym. Sci., Part A: Polym. Chem., 38, 247 (2000).

12. S.-H. Hsiao and C.-F. Chang, J. Polym. Sci., Part A: Polym. Chem., 34, 1433 (1996).

13. S.-H. Hsiao and C.-T. Li, J. Polym. Sci., Part A: Polym. Chem., 37, 1435 (1999).

14. S.-H. Hsiao, C.-P. Yang, and W.-L. Lin, Macromol. Chem. Phys., 200, 1428 (1999).

15. C.-P. Yang, S.-H. Hsiao, and H.-W. Yang, Macromol. Chem. Phys., 200, 1528 (1999).

16. S.-H. Hsiao and T.-L. Huang, Macromol. Chem. Phys., (submitted).

17. N. Yamazaki, F. Higashi, and J. Kawabata, J. Polym. Sci., Polym. Chem. Ed., 12, 2149 (1974).

18. N. Yamazaki, M. Matsumoto, and F. Higashi, J. Polym. Sci., Polym. Chem. Ed., 13, 1373 (1975). 